\title{
Spinal Epidural Arteriovenous Fistula with Perimedullary Venous Reflux: Clinical and Neuroradiologic Features of an Underestimated Vascular Disorder
}

\author{
(D) M. Mull, (D) A. Othman, (D) M. Dafotakis, DF.-J. Hans, (D) G.A. Schubert, and (D) F. Jablawi
}

\begin{abstract}
BACKGROUND AND PURPOSE: The purpose of this study was to discuss the clinical and radiologic characteristics of spinal epidural arteriovenous fistulas (SEAVF) and demonstrate their specific angiomorphology in a single-center series.
\end{abstract}

MATERIALS AND METHODS: Thirteen consecutive patients were diagnosed with SEAVF at RWTH Aachen University Hospital between 2006 and 2018 and were included in this study. All patients had MR imaging and DSA before treatment; 10 of these 13 patients received contrast-enhanced MRA (CE-MRA).

RESULTS: The mean patient age was $72 \pm 8$ years. Paraparesis was present in 12 (92\%) patients. Sphincter dysfunction and sensory symptoms were observed in 7 (54\%) and 6 (46\%) patients, respectively. The mean duration of symptoms was $6 \pm 8$ months. Congestive myelopathy on MR imaging was present in all patients. Prominent arterialized perimedullary veins were demonstrated in only 3 cases. CE-MRA revealed arterialized perimedullary veins and an arterialized epidural pouch in $9 / 10$ (90\%) patients, mostly located ventrolaterally. DSA demonstrated a multisegmental extension of the arterialized ventrolateral epidural pouch in 6 (46\%) cases. An intradural radicular drainage vein was localized distant from the original fistula point in $3(23 \%)$ patients.

CONCLUSIONS: Congestive myelopathy with an acute/subacute clinical course was the dominant finding in spinal epidural arteriovenous fistulas. CE-MRA is a powerful diagnostic tool for identifying arterialized perimedullary veins as well as an arterialized epidural pouch. While arterialized perimedullary veins frequently present with only mild enlargement and elongation in spinal epidural arteriovenous fistulas, the arterialized epidural pouch is frequently located ventrolaterally and may extend over several vertebral levels. DSA remains the criterion standard to precisely visualize a spinal epidural arteriovenous fistula and its intradural radicular drainage vein, which may be located distant from the fistulous point.

ABBREVIATIONS: AV = arteriovenous; $C E-M R A=$ contrast-enhanced MRA; SDAVF = spinal dural arteriovenous fistula; SEAVF = spinal epidural arteriovenous fistula

V

arious classifications have been established for spinal vascular malformations and fistulas based on their vascular supply, venous drainage pattern, and nidus location and morphology. The most common classification of spinal vascular diseases was developed by Oldfield and Doppman in 1988. ${ }^{1}$ They classified these

Received March 12, 2018; accepted after revision August 13.

From the Departments of Diagnostic and Interventional Neuroradiology (M.M., A.O., F.J.), Neurology (M.D.), and Neurosurgery (G.A.S.), University Hospital Aachen, RWTH Aachen University, Aachen, Germany; Department of Neurosurgery (F.J.), Justus-Liebig-University, Giessen, Giessen, Germany; Department of Diagnostic and Interventional Radiology (A.O.), University Hospital Tübingen, Tübingen, Germany; and Department of Neurosurgery (F.-J.H.), Paracelsus Kliniken, Osnabrück,

Germany.

Michael Mull and Ahmad Othman contributed equally to this work.

Please address correspondence to Michael Mull, MD, University Hospital Aachen, RWTH Aachen University, Department of Diagnostic and Interventional Neuroradiology, Pauwelstr 30, 52074 Aachen, Germany; e-mail: mmull@ukaachen.de

http://dx.doi.org/10.3174/ajnr.A5854 lesions into 4 types comprising classic spinal dural arteriovenous fistulas (SDAVFs), glomus arteriovenous malformations, congenital juvenile arteriovenous malformations, and perimedullary arteriovenous fistulas. The much rarer spinal epidural arteriovenous fistulas (SEAVFs) were not included in this classification.

In contrast to the SDAVF, the arteriovenous (AV) shunt in the SEAVF is located in the epidural space. The venous drainage of these AV shunts varies from pure epidural fistulas with extradural venous drainage to combined epidural and intradural venous reflux. ${ }^{2}$

A SEAVF with perimedullary venous reflux has been thought to present with nonspecific myelopathic symptoms comparable with those of a typical SDAVF. ${ }^{3,4}$ However, their precise angiographic and clinical presentations have not yet been investigated in a large number of patients and might still be unfamiliar to most neurologic and radiologic physicians.

A clear recommendation for treatment technique and strategy 
is also still lacking in the literature. The goal of treatment is, however, the interruption of the intradural radicular drainage vein to stop the arterialization of perimedullary veins and additionally the obliteration of the arterialized epidural pouch to decrease the risk of residual or recurrent fistula. These goals can be achieved either surgically or endovascularly.

To further characterize this extremely rare subgroup of fistulas, we identified 13 patients presenting with an SEAVF with perimedullary venous reflux to demonstrate their anatomic features and clinical and radiologic presentation.

\section{MATERIALS AND METHODS}

After obtaining permission from our local ethics board, we retrospectively evaluated the medical and radiologic reports of patients with an SEAVF diagnosed between January 2006 and February 2018 in RWTH Aachen University Hospital. All clinical data, including demographics and clinical presentation, were assessed by the treating physicians and re-evaluated for this study. In particular, we re-evaluated the neurologic status at time of admission to our institution, the duration of symptoms from onset until diagnosis, as well as previous misdiagnoses and treatment. The documented functional condition at time of discharge was rated as worse, stable, or improved.

All patients underwent spinal MR imaging $(n=13)$ and/or contrast-enhanced MRA (CE-MRA) $(n=10)$ before spinal angiography. Five (39\%) of these 13 patients underwent repetitive DSA for a definite diagnosis. As a rather new technique, C-arm flat panel CT was performed in the last 5 patients of this cohort.

Radiologic data were analyzed blinded to all clinical data by both the first and last author. The first author is an interventional neuroradiologist with $>30$ years' experience in spinal angiography and spinal vascular diseases; the last author is a consultant neurosurgeon with a many years' experience in clinical, radiologic, and surgical aspects of spinal vascular diseases. A reference standard for statistical analysis was established in a consensus reading. We retrospectively evaluated the arterial supply, venous drainage patterns, and location and extension of the arterialized epidural pouch in our DSA findings of all included patients.

\section{MR/CE-MRA Imaging}

MR imaging was performed in 7 patients at $1.5 \mathrm{~T}$ (Intera, Release 10:3; Philips Healthcare, Best, the Netherlands) and in 6 patients at $3 \mathrm{~T}$ (Prisma; Siemens, Erlangen, Germany) $(n=6)$ as part of the routine clinical work-up. Sagittal T2- and pre- and postcontrast T1-weighted images were obtained as well as axial T2- and contrast-enhanced T1 images of the thoracolumbar region. In 1 patient, examination was limited to the lumbar and deep thoracic regions only. The craniocaudal extension of the T2 signal hyperintensity and the medullary contrast enhancement were qualified by the number of vertebral levels shown to be affected on T1 and T2 MR images. The appearance of the perimedullary veins was rated subjectively as mild, moderate, or prominent due to their tortuous and dilated appearance in the T1 and T2 images.

Contrast-enhanced MR angiography was performed on a clinical 1.5T MR imaging system with a phased array spine coil in 4 patients. To emphasize the arterial phase of the bolus enhancement relative to the venous enhancement, we sampled the $k$-space using elliptic centric ordering, which allowed separation into arterial and mixed arterial-venous enhancement. Further details about this CE-MRA technique have been previously described by our group elsewhere. ${ }^{5,6}$

In 6 patients, time-resolved angiography with stochastic trajectories was performed on a clinical 3T MR imaging system. This CE-MRA also divides $k$-space into 2 regions but samples them alternately using a semi-randomized method. It allows a rapid acquisition of multiple images during the passage of the contrast bolus.

\section{DSA}

Selective spinal DSA was performed via a femoral approach in a dedicated biplanar neuroangiographic suite (Artis zee biplane; Siemens). Standardized angiography included selective manual injections of $4-5 \mathrm{~mL}$ of $300 \mathrm{mg} / \mathrm{mL}$ of iodinated nonionic contrast medium into the lumbar and intercostal arteries. If the preceding MRA examination suggested the level of a SEAVF, DSA protocol included at least injection of the segmental arteries, on both sides, 1 level above and below the suggested level. Imaging was in the anteroposterior direction with 2 frames per second. Oblique and lateral views were added to depict the morphology of the AV shunt as well as the intradural course of the draining vein. Film sequences of at least 5-20 seconds were obtained. Furthermore, 3D C-arm conebeam CT acquisitions (so-called Dyna-CT; Siemens) were performed in the last 5 patients in this cohort with a total acquisition time of 8 seconds. The arterial injection for the conebeam CT angiogram allowed both early and late opacification throughout the acquisition. MPRs were performed using an external postprocessing workstation.

The extension of the epidural pouch, the arterialized perimedullary veins, and the location of the perimedullary veins (dorsal, ventral) were analyzed on the basis of CE-MRA and DSA.

\section{RESULTS \\ Clinical Presentations}

Ten $(77 \%)$ of 13 patients were men. The mean age was $72 \pm 8$ years (median, 77 years; range, 59-83 years). Overall, 10 (77\%) patients presented with a relatively short clinical course $(<6$ months) with progressive motor weakness in the lower extremities. The remaining 3 (23\%) patients experienced a gradual onset and progressive deterioration of neurologic function. The mean interval between symptom onset and diagnosis was $6 \pm 8$ months (median, 3 months; range, 1-24 months) when excluding 1 statistical outliner in this series with a symptom duration of 60 months (Table 1).

The most common neurologic findings at admission in our institution were gait disturbances due to paraparesis in 12 (92\%) patients. The remaining $1(8 \%)$ patient had neurogenic claudication without manifest motor deficits. Eight $(62 \%)$ patients reported sphincter dysfunction at admission to our institution. Sensory symptoms in various severities were documented in 7 (54\%) patients and comprised diffuse loss of sensation and/or paresthesia in the lower extremities.

All 13 patients underwent microsurgical interruption at our center. Microsurgical dorsal lumbar decompressions and discectomies due to assumption of a spinal degenerative disease were 
Table 1: Clinical presentation of patients with spinal epidural arteriovenous fistula

\begin{tabular}{|c|c|c|c|c|}
\hline $\begin{array}{c}\text { Patient } \\
\text { No. }\end{array}$ & $\begin{array}{c}\text { Age } \\
(y r) / S e x\end{array}$ & $\begin{array}{c}\text { Duration of } \\
\text { Symptoms (mo) }\end{array}$ & Symptoms at Diagnosis & $\begin{array}{c}\text { Status } \\
\text { at Discharge }\end{array}$ \\
\hline 1 & $78, M$ & 6 & Paraparesis, sphincter dysfunction & Improved \\
\hline 2 & $63, M$ & 1 & Paraparesis, sphincter dysfunction hypesthesia below T10 & Stable \\
\hline 3 & $77, M$ & 1.5 & Paraparesis, hypesthesia L4, ataxia, sphincter dysfunction & Stable \\
\hline 4 & $60, \mathrm{~F}$ & 1.5 & Paraplegia, hypesthesia disturbances below T10 & Improved \\
\hline 5 & $68, \mathrm{~F}$ & 24 & Neurogenic claudication $<100 \mathrm{~m}$ & Improved \\
\hline 6 & $77, M$ & 1.5 & Paraplegia, hypesthesia below $\mathrm{L} 1$, sphincter dysfunction & Stable \\
\hline 7 & $64, \mathrm{~F}$ & 1 & Paraparesis, sphincter dysfunction & Improved \\
\hline 8 & $83, M$ & 60 & Paraparesis, hypesthesia, sphincter dysfunction & Stable \\
\hline 9 & $72, M$ & 0 & Paraparesis, hypesthesia, sphincter dysfunction & Stable \\
\hline 10 & $80, M$ & 12 & Paraparesis, sphincter dysfunction & Stable \\
\hline 11 & $77, \mathrm{M}$ & 2 & Paresis of left foot, ataxia & Stable \\
\hline 12 & $78, M$ & 3 & Paraparesis, hypesthesia & Stable \\
\hline 13 & $59, M$ & 5 & Ataxia & Stable \\
\hline
\end{tabular}

Table 2: Angiomorphologic characteristics of spinal epidural arteriovenous fistulas

\begin{tabular}{|c|c|c|c|c|c|c|}
\hline $\begin{array}{c}\text { Patient } \\
\text { No. }\end{array}$ & Arterial Feeder $^{\mathrm{a}}$ & $\begin{array}{c}\text { Origin of } \\
\text { Intradural Radicular } \\
\text { Drainage Vein }^{\mathrm{a}}\end{array}$ & $\begin{array}{c}\text { Extension } \\
\text { of Epidural } \\
\text { Pouch }^{\mathrm{b}}\end{array}$ & $\begin{array}{c}\text { Extension of } \\
\text { Arterialized } \\
\text { Perimedullary } \\
\text { Veins }^{b}\end{array}$ & $\begin{array}{c}\text { Location of } \\
\text { Arterialized } \\
\text { Perimedullary } \\
\text { Veins }^{b}\end{array}$ & $\begin{array}{l}\text { No. of } \\
\text { DSAs until } \\
\text { Diagnosis }\end{array}$ \\
\hline 1 & L3 R & L3 L & L3-L4 & $\mathrm{T} 8-\mathrm{T} 12$ & $\mathrm{D}=\mathrm{V}$ & 2 \\
\hline 2 & L3 bilateral, L4 L & L3 L & L2-L4 & $\mathrm{T} 3-\mathrm{T} 12$ & $\mathrm{D}=\mathrm{V}$ & 2 \\
\hline 3 & L1R & L1 R & L1 & ND & $\mathrm{D}<\mathrm{V}$ & 1 \\
\hline 4 & L3 bilateral & L3 R & L3 & T9-L1 & $\mathrm{D}>\mathrm{V}$ & 1 \\
\hline 5 & Left iliolumbar artery & S1 & S1 & $\mathrm{T} 7-\mathrm{T} 12$ & $D>V$ & 3 \\
\hline 6 & $\mathrm{~T} 10 \mathrm{~L}$ and $\mathrm{T} 11 \mathrm{~L}$ & L2 L & T 10-L3 & T6-L1 & $\mathrm{D}=\mathrm{V}$ & 3 \\
\hline 7 & L1 L & L2 L & L1-L2 & T3-T12 & $\mathrm{D}=\mathrm{V}$ & 1 \\
\hline 8 & $\mathrm{~T} 12 \mathrm{~L}$ & $\mathrm{~T} 12 \mathrm{~L}$ & $\mathrm{~T} 12 \mathrm{~L}$ & $\mathrm{TT1}$ & $D>V$ & 3 \\
\hline 9 & L3 L & L3 L & L3 L & $\mathrm{T} 6-\mathrm{T} 12$ & $\mathrm{D}<\mathrm{V}$ & 1 \\
\hline 10 & L4 R & L4 R & L2-L4 & T3-T10 & $\mathrm{D}=\mathrm{V}$ & 1 \\
\hline 11 & L3 L & S1 bilateral & L3-S1 & T10-L1 & $D>V$ & 1 \\
\hline 12 & L3 R & L3 R & L3 R & T9-T12 & $\mathrm{D}<\mathrm{V}$ & 1 \\
\hline 13 & L1 R & L1R & L1R & T10-L1 & $D>V$ & 1 \\
\hline
\end{tabular}

Note:-D indicates dorsal to spinal cord; $V$, ventral to spinal cord; L, left; R, right; ND, no data.

a DSA.

${ }^{b}$ MRA/DSA.

performed elsewhere before a definite diagnosis in $3(23 \%)$ of these 13 patients.

\section{Radiologic Findings}

Data of preoperative MR images were available in all 13 patients (Table 2). There was a centromedullary multisegmental T2WI hyperintense signal with involvement of the conus medullaris in all patients (mean, 7 vertebral levels; range, 1-13 vertebral levels). Intramedullary contrast enhancement was present in 10/12 (83\%) patients (mean, 3 vertebral levels; range, 1-10 vertebral levels).

Enlargement and elongation of arterialized perimedullary veins in the thoracic and/or thoracolumbar region were detected in various manifestations in all patients, mild in $6(50 \%)$, moderate in $3(25 \%)$, and prominent in the remaining 3 (25\%) patients. The arterialized perimedullary veins were localized predominately dorsal to the spinal cord in $5(42 \%)$ and ventrally in 3 $(25 \%)$. In the other 5 patients, arterialized perimedullary veins were observed dorsal and ventral to the spinal cord. In 9 (90\%) of 10 patients who underwent CE-MRA before DSA at our center, the arterialized ventrolateral epidural pouch was additionally detected, triggering the diagnosis of an SEAVF.

In 5 patients, $>2$ DSA examinations were necessary to establish the diagnosis of SEAVF (Table 2).

Angiographically, 10 (77\%) of the 13 fistulas were in the lum- bar region, and 2, (15\%) in the lower thoracic region below T10, respectively. The remaining ( $8 \%$ ) fistula was located in the sacral region. The arterialized ventrolateral epidural pouch in $6(46 \%)$ of 13 patients extended over several vertebral levels (mean, 2 vertebral levels; range, $1-3$ vertebral levels). Multiple arterial feeders were detected in 3 (23\%) patients.

Furthermore, the intradural radicular drainage vein originated in 3 (23\%) patients distant from the level of the fistula-feeding segmental artery, ipsilaterally in 2, patients 6 and 7, and bilaterally in patient 11 (range, 1-3 vertebral levels) (Table 2).

\section{DISCUSSION}

\section{Definition and Pathogenic Aspects of SEAVF}

Arteriovenous disorders of the epidural venous plexus have been rarely reported in the literature. ${ }^{2,7,8}$ Paraspinal AV shunts were first clearly described by Cognard et $\mathrm{al}^{9}$ in 2 patients with retrograde filling of intradural veins. The first SEAVF in our institution was diagnosed in 2006 and reported elsewhere. ${ }^{10}$ Since then, SEAVFs have been more frequently diagnosed in our center. The finding might reflect a better understanding of this particular vascular disorder as well as the growing diagnostic impact of spinal MR angiography.

The angioarchitecture, namely the feeding arteries, the venous 

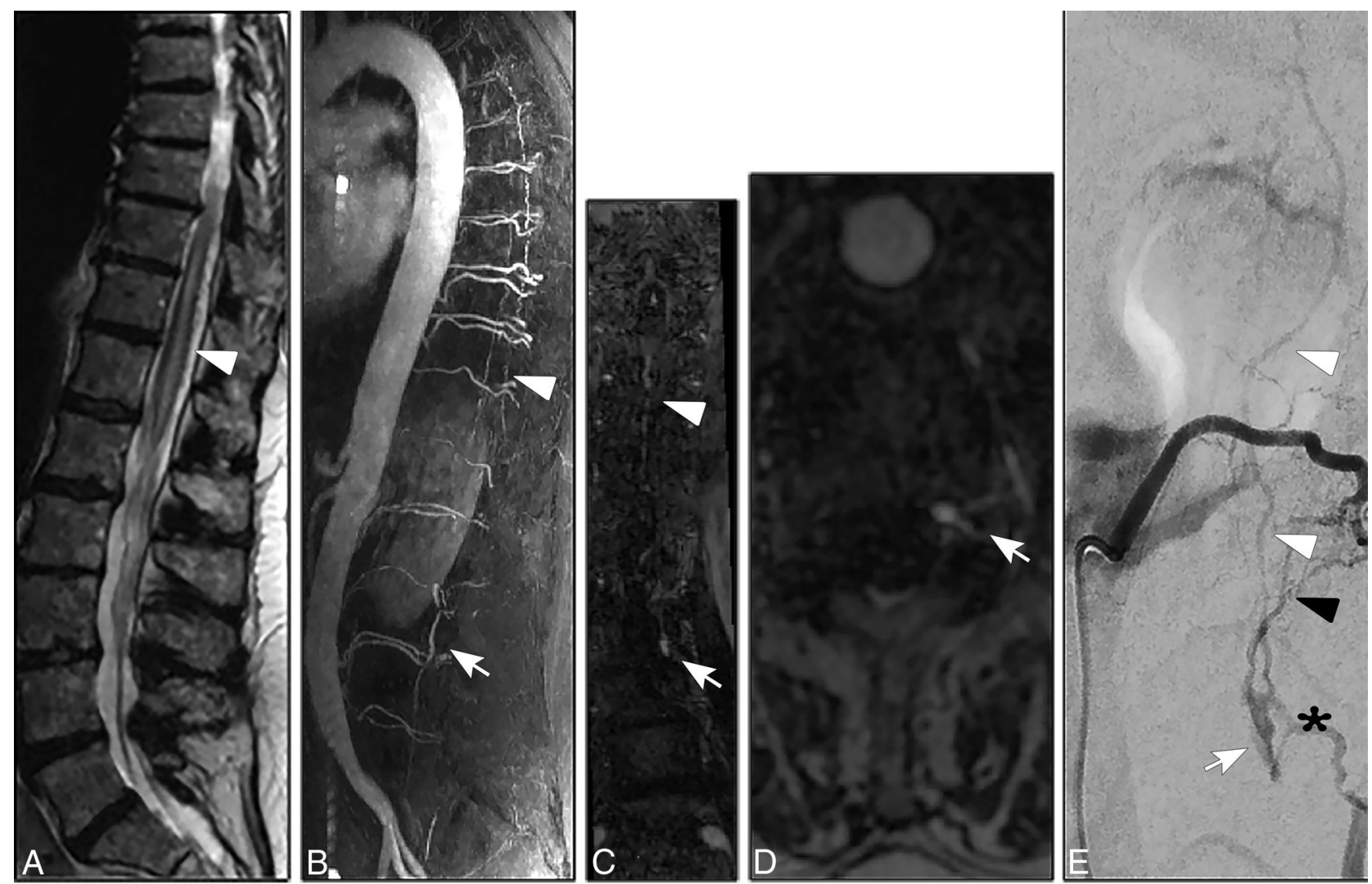

FIG 1. A, Sagittal T2- weighted images (3T; T2-TSE; slice thickness, $3 \mathrm{~mm}$ ) reveal extensive congestive myelopathy (white arrowhead). $B-D$, Spinal CE-MRA (3T; time-resolved imaging with strochastic trajectories (TWIST); sagittal MIP; coronal and axial MPR) shows arterialized pouch in the lumbar ventrolateral epidural space (white arrows) in association with arterialized perimedullary veins in the thoracic region (white arrowheads) suspicious for a SEAVF in the lumbar region. E, DSA in lateral projection shows a SEAVF (white arrow) supplied via branches of the left L2 segmental artery (black arrowhead) and drained via the respective intradural radicular vein (white arrowheads). Note the extraspinal venous outlet (asterisk).

drainage pattern, and the location of the AV shunt itself, differentiate these SEAVFs from the more frequent SDAVF. ${ }^{8}$

Concerning the angioarchitecture in SEAVF, the blood supply of the epidural arterial arcade is usually derived from numerous osseous and epidural branches of the segmental arteries with multisegmental and/or collateral anastomoses running along the spinal epidural space. ${ }^{711}$ In contrast, SDAVFs are usually supplied via radiculomeningeal branches of the radicular arteries, which run within the dural sleeve of the respective nerve roots. ${ }^{12}$

The venous drainage in SEAVF can occur epidurally and transdurally via an intradural radicular drainage vein into the perimedullary venous plexus, in contrast to the venous drainage in classic SDAVF, which occurs exclusively transdurally into the perimedullary venous plexus. ${ }^{2}$

Concerning the location of the AV shunt, the fistulous zone in all our patients was in the ventral and ventrolateral epidural spaces with variable craniocaudal extension of the arterialized epidural pouch along several vertebral levels (Fig 1).

In 1 patient, the epidural shunt was even more complex, crossing the midline; multiple compartments of the epidural plexus were filled ventrally as well as the contralateral intradural radicular vein on the same vertebral level (Fig 2).

The frequent ventral/ventrolateral location of the arterialized ventrolateral epidural pouch in an SEAVF could be explained by the rich venous anastomoses of the relatively wide ventral epidural space in the thoracic and lumbar regions. ${ }^{13}$ The posterior venous plexus is not well-appreciated angiographically and is not regularly involved in any pathologic process. ${ }^{3,14}$ In contrast to the SEAVF, the $\mathrm{AV}$ shunt in a classic SDAVF is usually located within the dural sleeve of the nerve root dorsolaterally in the thoracolumbar region and mainly ventrolaterally in the deep lumbosacral region., ${ }^{5,15}$

Nonetheless, the precise pathomechanism of the transdural venous drainage in both SDAVFs and SEAVFs is still unclear. ${ }^{15,16}$ An anti-reflux-impeding mechanism between both the epidural and perimedullary venous systems has been a matter of dispute in various anatomic studies. ${ }^{12,17-21}$ Tadié et $\mathrm{al}^{17}$ reported an antibackflow system within the transdural course of the radicular veins, resulting from narrowing and zigzagging of the vein walls while crossing the dura. Thron et al ${ }^{12}$ differentiated 2 types of transdural venous courses: a slit-like and a zigzag bulgy type. Both types of transdural venous courses might act as a valve protecting against reflux from the epidural into the coronal venous plexus. ${ }^{10,12}$ Nonetheless, due to the valveless venous walls of the epidural plexus, it is also conceivable that this anti-reflux mechanism might decompensate under high-pressure conditions and the venous blood could flow in either direction. ${ }^{18,19,21-23} \mathrm{~A}$ retrograde filling of radicular veins from the epidural venous plexus has also been observed in a few anatomic studies. ${ }^{10,12,17,19,24,25}$ Moreover, during spinal DSAs and epidural phlebography, epidural shunts without reflux into the perimedullary veins have been occasionally visualized. ${ }^{15}$ 

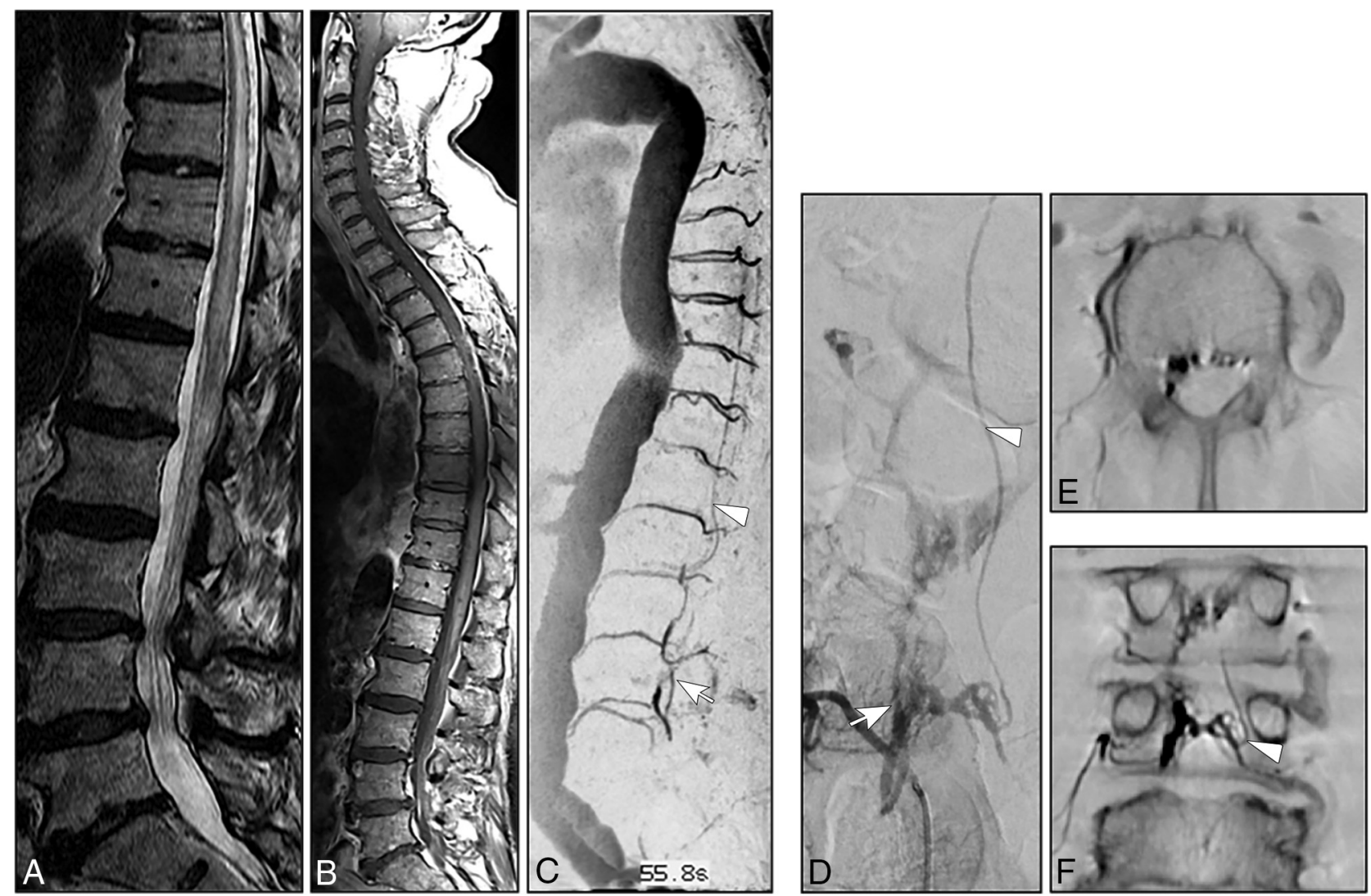

FIG 2. A-B, Sagittal T2- and contrast-enhanced T1-weighted images (3T; T2-TSE; T1-TSE; slice thickness, 3 mm) show extensive congestive thoracic myelopathy. C, Spinal CE-MRA (sagittal MIP) reveals an abnormal arterialized epidural pouch in the lumbar region (white arrow) in addition to thoracic arterialized perimedullary veins (white arrowhead). D, DSA (posteroanterior projection) exams identify the fistula in the epidural space on the vertebral level of L4 (white arrow), supplied via the right L4 segmental artery and drained by the contralateral L4 intradural radicular vein (white arrowhead). $E$ and $F$, Axial and coronal MPR of DynaCT, $2 \mathrm{~mm}, 8$ seconds rotation: Note the multisegmental and bilateral extension of the arterialized epidural pouch and the left sided origin of the intradural radicular drainage vein crossing the dura at the contralateral neural foramen (white arrowhead).

On the basis of these observations, one could assume that epidural shunts might occur more frequently than previously thought, but they often remain asymptomatic as long as the transdural anti-reflux mechanism remains intact. ${ }^{10,12}$

An intravenous stasis and/or acute hydrostatic disturbances within these arterialized elongated epidural compartments might reinforce the development of venous thrombosis. This may, in turn, induce acute disruption of the dural anti-reflux mechanisms causing transdural venous drainage and subsequent congestive myelopathy. ${ }^{26}$ Supporting this hypothesis, the origin of the arterialized radicular vein in $3(23 \%)$ patients in our series was caudal to the epidural AV shunt (Fig 3).

\section{Clinical Presentation}

Due to the extremely low incidence of SEAVFs, clinical presentations of these lesions have been rarely reported systematically in larger sample series. ${ }^{14,27}$ Most patients in our study presented with motor weakness of the lower extremities, sphincter dysfunction, and sensory disturbances (Table 1) at admission. After treatment, clinical symptoms of most patients in our study stabilized or were mildly improved at discharge. ${ }^{14,27}$ This result is in accordance with those in case series reported by Kiyosue et $\mathrm{al}^{14}$ and Nasr et al. ${ }^{27}$

Due to the arterialization of the perimedullary venous plexus, several progressive pathophysiologic changes can occur in the spinal cord and its vessels, such as hyalinization, vascular calcification, necrosis, and gliosis, all potential contributors to irreversible functional deterioration of the spinal cord. ${ }^{28-30}$

One major finding in our current analysis was the relatively rapid clinical course of SEAVFs compared with classic SDAVFs. This might be triggered by acute hemodynamic changes of the venous outflow of the spinal cord caused by thrombosis and/or hydrostatic changes in the epidural and perimedullary venous plexus. $^{7}$

\section{Radiologic Findings}

The hallmarks of SEAVFs on MR imaging in our current cohort were the following: 1) congestive thoracolumbar myelopathy with a high rate of conus medullaris involvement, 2) a predominantly nonprominent appearance of the pathologically arterialized perimedullary veins in most cases (75\%), and 3) the presence of ventrally/ventrolaterally located arterialized epidural venous pouches detected in 9 of 10 patients with CE-MRA preceding DSA.

The value of CE-MRA in diagnosing an SDAVF has been previously reported by our group. ${ }^{6}$ In a series of 19 patients with SDAVFs, the correct localization could be achieved in 14 (74\%) patients. In the remaining 5 patients, a mismatch of only 1 vertebral level was noted. ${ }^{6}$ Our current findings are supported by 

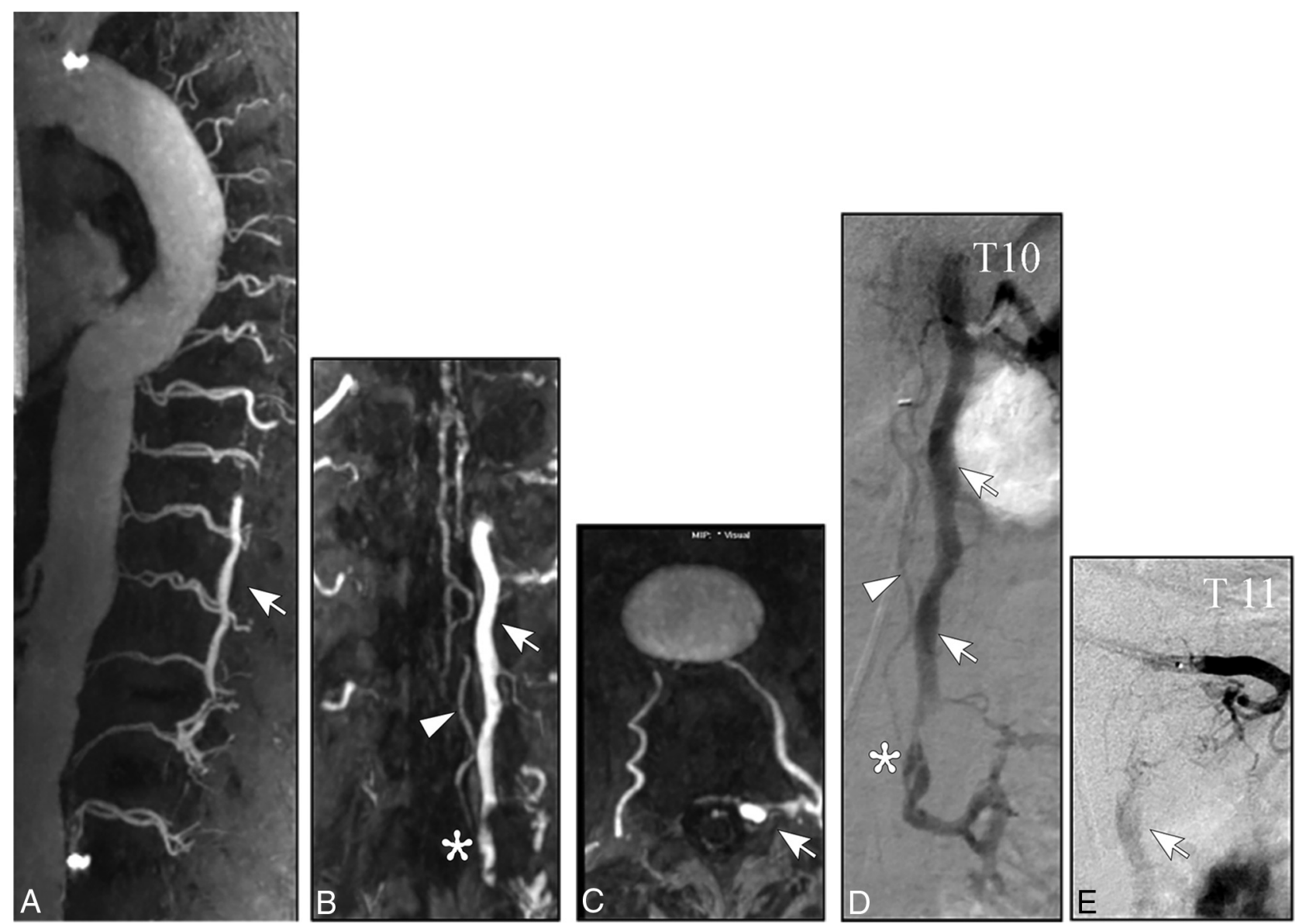

FIG 3. A, Spinal CE-MRA (1.5 T, sagittal MIP) reveals an extensive pathological arterialization of a ventrolateral epidural venous pouch extending over four vertebral levels (white arrow). B-C, Further reconstructions of the source MRA images (coronal and axial MPR) demonstrate precisely the epidural pouch (white arrow) and show the filling of the intradural radicular drainage vein (white arrowhead). D-E, DSA exams (posteroanterior projections) identify the multisegmental ventrolateral epidural pouch of the SEAVF (white arrow) with multiple left-sided arterial feeders supplied by the thoracic segmental arteries T 10 and T 11. Note the distant origin of the intradural radicular drainage vein (asterisk).

Mathur et al, ${ }^{31}$ who recently observed, in a series of 7 patients with SEAVFs, a high accuracy and reliability of CE-MRA for identification and localization of these lesions.

DSA is, however, still regarded as a basic diagnostic tool for the angiomorphologic, pretherapeutic evaluation in spinal AV fistulas and malformations. ${ }^{6,32-34}$ In 5 (38\%) of 13 patients, even repetitive spinal DSA remained inconclusive and did not sufficiently depict the suspected AV shunt before referral to our center.

Based on our experience, reasons for this failure rate were insufficient opacification of the respective segmental artery based on atherosclerosis and anatomic obstacles and a too-short DSA series, resulting in missing the intradural radicular and/or perimedullary veins. Moreover, 4 of these 5 patients did not undergo spinal CE- MRA initially, which may have facilitated the diagnosis via subsequent DSA.

Spinal angiography offers a dynamic visualization of the angioarchitecture of vascular malformations, including the arterial feeders, the morphology of AV shunts/venous pouches, and the draining veins. $^{32}$

Overall, 12 (92\%) fistulas were located in the thoracolumbar region and were supplied by segmental arteries. The remaining $(8 \%)$ fistula was located in the sacral region and was supplied by branches of the left iliolumbar artery. Also, multisegmental or collateral arterial feeders of the arterialized ventrolateral epidural pouch were present in 3 (23\%) of our patients. In contrast, of 196 patients with SDAVFs treated at our center between 1990 and 2017 , only $9(4.6 \%)$ fistulas presented with a multisegmental or bilateral arterial supply. ${ }^{5,35}$

The predominant thoracolumbar location of SEAVFs and the higher rate of multiple arterial feeders of SEAVFs compared with classic SDAVFs could also be explained by the wide epidural space and the rich epidural anastomotic arterial network in this region. $3,7,13$

The arterialized epidural pouch extended over several vertebral levels in $6(46 \%)$ patients. The intradural radicular drainage vein in 3 of these 6 patients was distant from the epidural fistulous point. This multisegmental distance between the fistulous feeding artery and the origin of the intradural radicular drainage vein has never been previously observed in any classic SDAVF at our center. $^{15,35}$

Because the main goal of treatment of SEAVF is the disconnection of the intradural radicular drainage vein as well as the complete interruption of arterialized epidural compartments, the precise localization of the intradural radicular drainage vein in SEAVF is essential to reduce the risk of residual or recurrent fistulas irrespective of the treatment technique and strategy. 


\section{Limitations}

A major limitation of our study is the small sample size and the retrospective approach. Because spinal epidural arteriovenous fistulas are a very rare but clinically relevant entity, our results may, nevertheless, serve as an orientation for future studies, in particular because there are scarce data concerning this topic in large cohorts in the literature.

\section{CONCLUSIONS}

Congestive myelopathy with an acute or subacute clinical course is a dominant finding in SEAVFs. The presence of myelopathic symptoms combined with medullary venous congestion with or without contrast enhancement on MR imaging should require CE-MRA, even in cases of nonprominent perimedullary veins. In SEAVFs, CE-MRA is a powerful noninvasive diagnostic tool to identify the epidural AV shunt itself and detect arterialized perimedullary veins. DSA remains obligatory for the angiomorphologic analysis of the epidural AV shunt, which frequently extends ventrolaterally over several vertebral levels. DSA is mandatory for identifying the origin of the intradural radicular drainage vein that may be located distant from the epidural fistulous point.

Disclosures: Ahmed Othman-UNRELATED: Grants/Grants Pending: Bayer Healthcare, unrestricted grant*; Payment for Lectures Including Service on Speakers Bureaus: GE Healthcare, speakers bureaus. Gerrit Alexander Schubert-UNRELATED: Payment for Lectures Including Service on Speakers Bureaus: Braun Aesculap. *Money paid to the institution.

\section{REFERENCES}

1. Oldfield EH, Doppman JL. Spinal arteriovenous malformations. Clin Neurosurg 1988;34:161-83 Medline

2. Clarke MJ, Patrick TA, White JB, et al. Spinal extradural arteriovenous malformations with parenchymal drainage: venous drainage variability and implications in clinical manifestations. Neurosurg Focus 2009;26:E5 CrossRef Medline

3. Brinjikji W, Yin R, Nasr DM, et al. Spinal epidural arteriovenous fistulas. J Neurointerv Surg 2016;8:1305-10 CrossRef Medline

4. Aminoff MJ, Logue V. The prognosis of patients with spinal vascular malformations. Brain 1974;97:211-18 CrossRef Medline

5. Jablawi F, Nikoubashman O, Schubert GA, et al. Clinical and radiologic characteristics of deep lumbosacral dural arteriovenous fistulas. AJNR Am J Neuroradiol 2018;39:392-98 CrossRef Medline

6. Mull M, Nijenhuis RJ, Backes WH, et al. Value and limitations of contrast-enhanced MR angiography in spinal arteriovenous malformations and dural arteriovenous fistulas. AJNR Am J Neuroradiol 2007;28:1249-58 CrossRef Medline

7. Silva N Jr, Januel AC, Tall P, et al. Spinal epidural arteriovenous fistulas associated with progressive myelopathy: report of four cases. J Neurosurg Spine 2007;6:552-58 CrossRef Medline

8. Rangel-Castilla L, Holman PJ, Krishna C, et al. Spinal extradural arteriovenous fistulas: a clinical and radiological description of different types and their novel treatment with Onyx. J Neurosurg Spine 2011;15:541-49 CrossRef Medline

9. Cognard C, Semaan H, Bakchine S, et al. Paraspinal arteriovenous fistula with perimedullary venous drainage. AJNR Am J Neuroradiol 1995;16:2044-48 Medline

10. Krings T, Mull M, Bostroem A, et al. Spinal epidural arteriovenous fistula with perimedullary drainage: case report and pathomechanical considerations. J Neurosurg Spine 2006;5:353-58 CrossRef Medline

11. Lasjaunias P, Berenstein A, Raybaud C. Surgical Neuroangiography. Berlin: Springer-Verlag; 1990

12. Thron A, Krings T, Otto J, et al. The transdural course of radicular spinal cord veins: a microangiographical and microscopical study. Clin Neuroradiol 2015;25:361-69 CrossRef Medline

13. Takai K, Taniguchi M. Comparative analysis of spinal extradural arteriovenous fistulas with or without intradural venous drainage: a systematic literature review. Neurosurg Focus 2012;32:E8 CrossRef Medline

14. Kiyosue $H$, Tanoue $S$, Okahara $M$, et al. Spinal ventral epidural arteriovenous fistulas of the lumbar spine: angioarchitecture and endovascular treatment. Neuroradiology 2013;55:327-36 CrossRef Medline

15. Thron AK. Applications in spinal dural AV fistulas. In: Thron A. Vascular Anatomy of the Spinal Cord: Radioanatomy as the Key to Diagnosis and Treatment. 2nd ed. Cham: Springer International Publishing; 2016

16. Jablawi F, Nikoubashman O, Mull M. Arterial hypertension is associated with symptomatic spinal dural arteriovenous fistulas. World Neurosurg 2017;103:360-63 CrossRef Medline

17. Tadié M, Hemet J, Freger P, et al. Morphological and functional anatomy of spinal cord veins [in French]. J Neuroradiol 1985;12: 3-20 Medline

18. Merland JJ, Riche MC, Chiras J. Intraspinal extramedullary arteriovenous fistulae draining into the medullary veins [in French]. J Neuroradiol 1980;7:271-320 Medline

19. van der Kuip M, Hoogland PV, Groen RJ. Human radicular veins: regulation of venous reflux in the absence of valves. Anat Rec 1999; 254:173-80 CrossRef Medline

20. Groen RJ, du Toit DF, Phillips FM, et al. Anatomical and pathological considerations in percutaneous vertebroplasty and kyphoplasty: a reappraisal of the vertebral venous system. Spine 2004;29:1465-71 CrossRef Medline

21. Groen RJ, Grobbelaar M, Muller CJ, et al. Morphology of the human internal vertebral venous plexus: a cadaver study after latex injection in the 21-25-week fetus. Clin Anat 2005;18:397-403 CrossRef Medline

22. Clemens HJ, Vogelsang H. Transosseous phlebography of the vertebral column and spinal canal: morphological and clinical aspects [in German]. Verh Anat Ges 1970;64:179-80 Medline

23. Vogelsang H, Pia HW. Importance of spinal angiography for the diagnosis of spinal angioma [in German]. Fortschr Geb Rontgenstr Nuklearmed 1965;102:661-66 Medline

24. Behrens S, Thron A. Long-term follow-up and outcome in patients treated for spinal dural arteriovenous fistula. J Neurol 1999;246: 181-85 CrossRef Medline

25. Jürgen O. Morphologie des Sperrmechanismus am Duradurchtritt der Venae Radiculares des Menschen: neuroradiologische und histologische Befunde [doctoral thesis]. Achen: Faculty of Medicine, RWTH Aachen University; 1990

26. Jablawi F, Schubert GA, Hans FJ, et al. Anticoagulation therapy after surgical treatment of spinal dural arteriovenous fistula: effectiveness and long-term outcome analysis. World Neurosurg 2018;114: e698-705 CrossRef Medline

27. Nasr DM, Brinjikji W, Clarke MJ, et al. Clinical presentation and treatment outcomes of spinal epidural arteriovenous fistulas. J Neurosurg Spine 2017;26:613-20 CrossRef Medline

28. Hurst RW, Kenyon LC, Lavi E, et al. Spinal dural arteriovenous fistula: the pathology of venous hypertensive myelopathy. Neurology 1995;45:1309-13 CrossRef Medline

29. Benhaiem N, Poirier J, Hurth M. Arteriovenous fistulae of the meninges draining into the spinal veins: a histological study of 28 cases. Acta Neuropathol 1983;62:103-11 CrossRef Medline

30. Rodriguez FJ, Crum BA, Krauss WE, et al. Venous congestive myelopathy: a mimic of neoplasia. Mod Pathol 2005;18:710-18 CrossRef Medline

31. Mathur S, Symons SP, Huynh TJ, et al. First-pass contrast-enhanced MRA for pretherapeutic diagnosis of spinal epidural arteriovenous fistulas with intradural venous reflux. AJNR Am J Neuroradiol 2017; 38:195-99 CrossRef Medline 
32. Thron A. Spinal dural arteriovenous fistulas [in German]. Radiologe 2001;41:955-60 Medline

33. Gilbertson JR, Miller GM, Goldman MS, et al. Spinal dural arteriovenous fistulas: MR and myelographic findings. AJNR Am J Neuroradiol 1995; 16:2049-57 Medline

34. Thron A, Mull M, Reith W. Spinal arteriovenous malformations [in German]. Radiologe 2001;41:949-54 CrossRef Medline
35. Mull M. Durchblutungsstörungen des Rückenmarks: Neurologische Untersuchungen zur Pathogenese und Strategien der Diagnosesicherung. Department of Diagnostic and Interventional Neuroradiology, University Hospital Aachen. 2004 https://www.researchgate.net/ publication/33987973_Durchblutungsstorungen_des_Ruckenmarks_ neuroradiologische_Untersuchungen_zur_Pathogenese_und_ Strategien_der_Diagnosesicherung. Accessed January 20, 2004 